\title{
Development and Validation of a UV/vis Spectrometric Method for Determination of Cefixim Trihydrate in Raw Materials (Pure) and Tablet Forms
}

\author{
Mavanga Mabaya Timothy ${ }^{1}$, Mankulu Kakumba Jocelyn², Mayangi Makola Mannix², \\ Mbenza Puati Adelard², Mana Kialengila Didi², Mavar Tayey Mbay Jean², \\ Mbinze Kindenge Jeremi ${ }^{1, *}$ \\ ${ }^{1}$ Laboratory of drugs and health products analysis, Faculty of Pharmaceutical Sciences, University of Kinshasa, Kinshasa XI, Democratic \\ Republic of the Congo \\ ${ }^{2}$ Laboratory of quality control and drugs analysis and diets survey, Faculty of Pharmaceutical Sciences, University of Kinshasa, Kinshasa XI, \\ Democratic Republic of the Congo
}

\section{Email address:}

jeremiembinze@gmail.com (M. K. Jeremi)

${ }^{*}$ Corresponding author

\section{To cite this article:}

Mavanga Mabaya Timothy, Mankulu Kakumba Jocelyn, Mayangi Makola Mannix, Mbenza Puati Adelard, Mana Kialengila Didi, Mavar Tayey Mbay Jean, Mbinze Kindenge Jeremi. Development and Validation of a UV/vis Spectrometric Method for Determination of Cefixim Trihydrate in Raw Materials (Pure) and Tablet Forms. International Journal of Pharmacy and Chemistry. Vol. 7, No. 2, 2021, pp. 31-36. doi: $10.11648 /$ j.ijpc.20210702.12

Received: March 13, 2021; Accepted: March 30, 2021; Published: April 13, 2021

\begin{abstract}
A Cefixim Trihydrate method was developed and validated for determination of Cefixim in raw materials and tablets. This was to enable quantification of the compound using an available and less expensive analytical method for those forms. Henceforth, this study aimed to develop and validate a fast, simple and economical Ultraviolet-visible (UV/vis) spectrophotometric method for the quantitative estimation of Cefixim in pure state and in tablet forms. The predicted wavelength for maximal absorption to perform with this method was $286 \mathrm{~nm}$ with $0.1 \mathrm{~N} \mathrm{HCl}$ as solvent and blank. This gave useful results for the following steps. Linearity, precision, accuracy, specificity, robustness, limit of detection (LOD) and limit of quantification (LOQ) were evaluated for the method validation according to the International Conference on Harmonization (ICH) requirements. The developed method was used for the quantitative determination of Cefixim tablets marketed on the local market. The calibration data showed a better correlation $\left(\mathrm{R}^{2}=1\right)$ over the range of concentrations used $(2.5-15 \mu \mathrm{g} / \mathrm{ml})$ and the regression equation was $\mathrm{Y}=0.0511 \mathrm{X}$. The limits of detection (LOD) and quantification (LOQ) determined were 0.275 $\mu \mathrm{g} / \mathrm{ml}$ and $0.919 \mu \mathrm{g} / \mathrm{ml}$, respectively. The accuracy study carried out at three concentration levels $(80 \%, 100 \%$, and $120 \%)$ gave respective recovery rate averages of $97.25 \%, 97.56 \%$ and $97.44 \%$ at which the relative standard deviations (RSD) were all less than $2 \%$. The intra and inter-day precision, specificity and robustness were also satisfactory.
\end{abstract}

Keywords: Cefixim Trihydrate, UV/vis, Spectrometry, Development, Validation

\section{Introduction}

Cefixim is one of beta-lactam family antibiotic, from the group of so-called 3rd generation cephalosporin's. Like others, its mechanism of action is based on inhibition of bacterial cell wall synthesis blocking the formation of peptidoglycan. Cefixim is described in the pharmacopoeias, especially in the British, American and European pharmacopoeias. Chemically, it is a $(6 \mathrm{R}, 7 \mathrm{R})-7-[[(\mathrm{Z})-2-(2-$ amino-thiazol-4-yl) -2 - [(carboxymethoxy) imino] acethyl] amono] -3- acid. ethenyl-8-oxo-5-thia-1-azabicyclo [4.2.0] oct-2-ene-carboxylic trihydrate, the structure of which is shown in figure 1 [1].

The American, British and European pharmacopoeias offer High Performance Liquid Chromatography as a separative technique for the analysis of this molecule in its pure state as a raw material or in its pharmaceutical formulations as tablet 
[1-3]. This advanced technique has a major disadvantage that it takes a lot of analysis time and is very expensive for the quality control laboratory, especially in developing countries. To overcome this difficulty, Babitan et al as well as Umme Bushra et al have each developed and validated a method for analyzing Cefixim using a non-separating technique which is Ultraviolet-visible spectrophotometry using methanol as a solvent [4]. A part from these previous researches, another Spectrometric Method using Methanol and water as solvent was developed, to deal with analysis of Cefixim in $287 \mathrm{~nm}$ as maximal wavelength to the measurement [5]. The method is simple and less expensive than Liquid Chromatography but requires the use of organic solvent which costs more. Keeping this in mind, the development of a UV/vis spectrophotometric method using $\mathrm{HCl}$ diluted as solvent would be necessary to help the quality control laboratory in developing countries to easily analyze this molecule.<smiles>C=CC1=C(C(=O)O)N2C(=O)[C@H](NC(=O)/C(=N\OCC(=O)O)c3csc(N)n3)[C@H]2SC1</smiles>

Figure 1. Cefixim Chemical Structure.

In this context, this study mainly aimed to develop a simple and less expensive method for Cefixim determination using the UV/vis spectrophotometric method. Then, validate the developed method according to the International Conference on Harmonization (ICH) [6] before its application on real samples.

\section{Materials and Methods}

\subsection{Materials and Reagents}

We used the Thermo Scientific UV/vis spectrophotometer and an analytical branded balance Gram Precision serie SV.

Pure Cefixim was purchased from Fagron NV (Waregen, Belgium), batch: 14E3549, degree of purity: $100.2 \%$. The Cefixim tablet (CEFI-200) was purchased on the local market in Kinshasa (DR Congo). Hydrochloric acid (Merck KGaA, Germany) and formic acid (Merck KGaA, Germany) were all analytical grade.

\subsection{Methods}

\subsubsection{Preparation of 0.1M Hydrochloric Acid}

In a $1000 \mathrm{ml}$ volumetric flask, dissolve a hydrochloric acid volume corresponding to $4.2 \mathrm{~g}$ of $\mathrm{HCl}$ in a sufficient quantity of carbon dioxide-free water; adjust the volume to the gauge line with the same solvent [7].

\subsubsection{Preparation of the Stock Solution of Cefixim Trihydrate}

The stock solution of Cefixim was prepared by dissolving
$25 \mathrm{mg}$ of the substance exactly weighed in $3 \mathrm{ml}$ of formic acid contained in a $200 \mathrm{ml}$ volumetric flask and subsequently adjusting the volume to the mark with hydrochloric acid $0,1 \mathrm{~N}$ finally to obtain a concentration of $125 \mu \mathrm{g} / \mathrm{ml}$. Subsequent dilutions were made with $0.1 \mathrm{~N} \mathrm{HCl}$ solution.

\subsubsection{Determination of the Maximum Absorption Wavelength $\lambda_{\text {max }}$}

An adequate volume of the standard solution was diluted with $0.1 \mathrm{~N}$ hydrochloric acid solution to obtain an essay solution for determination of the maximal absorption wavelength of the compound. Indeed, Cefixim Trihydrate showed a maximum absorption at $286 \mathrm{~nm}$.

\subsubsection{Preparation of Solution for Method Validation}

The proposed Method was validated following different criteria such as linearity, precision, accuracy, specifity, robustessness, LOD, LOQ and Essay [8].

\section{(i) Solution for the Linearity of the Method}

Aliquots of the stock solution containing $125 \mu \mathrm{g} / \mathrm{ml}$ of Cefixim were successively diluted with $0.1 \mathrm{~N} \mathrm{HCl}$ solution to finally obtain respective concentrations of $2.5 \mu \mathrm{g} / \mathrm{ml} ; 5 \mu \mathrm{g} / \mathrm{ml}$; $7.5 \mu \mathrm{g} / \mathrm{ml} ; 10 \mu \mathrm{g} / \mathrm{ml} ; 12.5 \mu \mathrm{g} / \mathrm{ml}$ and $15 \mu \mathrm{g} / \mathrm{ml}$. Absorbances were measured at $286 \mathrm{~nm}$. The regression line was constructed by integrating the means of the three consecutive days; Absorbances against those of the respective concentrations $[9,10]$.

The figure 2 illustrates the shape of the obtained line.

\section{(ii) Solution for the Specificity of the Method}

To assess the specificity of the method, a placebo mixture consisting of $25 \mathrm{mg}$ of starch, $25 \mathrm{mg}$ of magnesium stearate, $25 \mathrm{mg}$ of talc and $25 \mathrm{mg}$ of microcrystalline cellulose was placed in a $200 \mathrm{ml}$ volumetric flask containing $3 \mathrm{ml}$ of formic acid; the mixture was then stirred in an ultrasonic bath for 5 minutes and the volume was adjusted to the mark with $0.1 \mathrm{~N}$ $\mathrm{HCl}$. After filtration using Whattmann filter paper $\left(\mathrm{N}^{\circ} 41\right)$, $3.2 \mathrm{ml} ; 4 \mathrm{ml}$ and $4.8 \mathrm{ml}$ of filtrate were respectively placed in three $50 \mathrm{ml}$ volumetric flasks and $4 \mathrm{ml}$ of Cefixim standard solution was added in each of three volumetric flasks finally to obtain $80 \% ; 100 \%$ and $120 \%$ each of the constituent of the placebo mixture after adjusting the volume to the gauge line [11]. The calculated recovery rate, standard deviations (SD) and relative standard deviations (RSD) are shown in Table 1. In addition, as shown in Figure 2, the placebo mixture did not absorb at length $\mathrm{d}$ wave used in the developed method.

\section{(iii) Solution for Method Accuracy}

The intra-day and inter-day precision of the proposed method was evaluated by analyzing 6 times three different concentrations $(2.5 ; 5$ and $7.5 \mu \mathrm{g} / \mathrm{ml})$ of the standard solution of Cefixim Trihydrate. The intra-day precision was determined the same. While the inter-day precision was determined on three consecutive days in the same week. Absorbances were measured and the mean concentrations found, the relative standard deviations (RSD) and the relative errors were calculated. The results are shown in Table 2 . 


\section{(iv) Solution for the Correctness of the Method}

The accuracy of the method was calculated by estimating the recovery rate at three concentration levels $(80 \% ; 100 \%$ and $120 \%$ ) by the standard addition method: a quantity of powder obtained from grinding of 20 tablets, equivalent to 25 $\mathrm{mg}$ of Cefixim (CEFI-200) were accurately weighed and transferred to a $200 \mathrm{ml}$ volumetric flask containing $3 \mathrm{ml}$ of formic acid. The mixture was stirred in an ultrasonic bath for 5 minutes, and then the volume was adjusted to the mark with $0.1 \mathrm{~N} \mathrm{HCl}$. After mixing and filtration using Wattmann filter paper $\left(\mathrm{N}^{\circ} 41\right), 4 \mathrm{ml}$ of pre-analyzed filtrate was transferred to three different $50 \mathrm{ml}$ volumetric flasks in which the Cefixim concentration was fortified with 3.2, respectively; 4 and $4.8 \mathrm{ml}$ of standard solution and the volume were adjusted to the mark with $0.1 \mathrm{~N} \mathrm{HCl}$ finally to obtain spiked solutions of respective concentrations of $80 \% ; 100 \%$ and $120 \%$. Absorbances were measured. The recovery rates were calculated using the following formula:

$$
\%=\mathrm{Cf}-\mathrm{C} \times 100 / \mathrm{Ca}
$$

Where $\mathrm{Cf}$ is the concentration of the fortified sample; $\mathrm{C}$, the concentration of the unfortified sample and $\mathrm{Ca}$, the concentration of the added substance [12]. The results are shown in Table 2.

\section{(v) Solution for the Robustness of the Method}

The robustness of a method is its ability to provide consistent results under changing conditions. In this study, robustness was demonstrated by measuring the Absorbances of the standard solution of $10 \mu \mathrm{g} / \mathrm{ml}$ while changing the maximum absorption wavelength by plus or minus one $\left(\lambda_{\max }\right.$ \pm 1 ) $[11,13-15]$. The measured absorbance means, standard deviations (SD) and relative standard deviations (RSD) were calculated. The results are shown in Table 4.

\section{(vi) Solution for Limit of Detection (LOD) and Limit of Quantification (LOQ)}

The limit of detection (LOD) and the limit of quantification (LOQ) of the proposed method were calculated on the basis of the data obtained from the study of linearity: the slopes of the regression line and the standard deviation were calculated, and the interception was known. The limit of detection (LOD) and the limit of quantification (LOQ) were determined using the following formulas according to the requirements of the International Harmonization Conference (ICH) $[6,10,16]$ :

$$
\begin{aligned}
L O D & =\frac{S_{b} \times 3}{S} \\
L O Q & =\frac{S_{b} \times 10}{S}
\end{aligned}
$$

Where, $\mathrm{S}_{\mathrm{b}}$ is the standard deviation of the intercept and $\mathrm{S}$ the slope of the regression line. The results are shown in Table 4

\section{(vii) Solution for the Dosage of Cefixim Tablet-200}

20 tablets were weighed one by one and their average weight was calculated. All of the tablets were crushed and reduced to an impalpable powder. A quantity of obtained powder corresponding to $25 \mathrm{mg}$ of Cefixim was exactly weighed and transferred to a $200 \mathrm{ml}$ volumetric flask containing $3 \mathrm{ml}$ of formic acid. After stirring the mixture in an ultrasonic bath for 5 minutes, the volume was adjusted to the mark with $0.1 \mathrm{~N} \mathrm{HCl}$ and then filtered using Wattmann filter paper $\left(\mathrm{N}^{\circ} 41\right)$. An adequate volume of filtrate was diluted to obtain a solution with a concentration of $10 \mu \mathrm{g} / \mathrm{ml}$. Absorbances were measured and concentrations, standard deviation (SD) and relative standard deviation (RSD) were calculated $(n=3)$. The results are shown in Table 5 .

\section{Results and Discussion}

The maximum absorption wavelength obtained was 286 $\mathrm{nm}$. The regression line $(\mathrm{Y}=0.0511 \mathrm{x})$ indicated an excellent linear correlation $\left(\mathrm{R}^{2}=1\right)$ over a range of concentrations $(2.5$ $15 \mu \mathrm{g} / \mathrm{ml}$ ) used (Figure 2). The limits of detection (LOD) and quantification (LOQ) calculated from the data of the linearity study are respectively equal to $0.275 \mu \mathrm{g} / \mathrm{ml}$ and $0.919 \mu \mathrm{g} / \mathrm{ml}$.

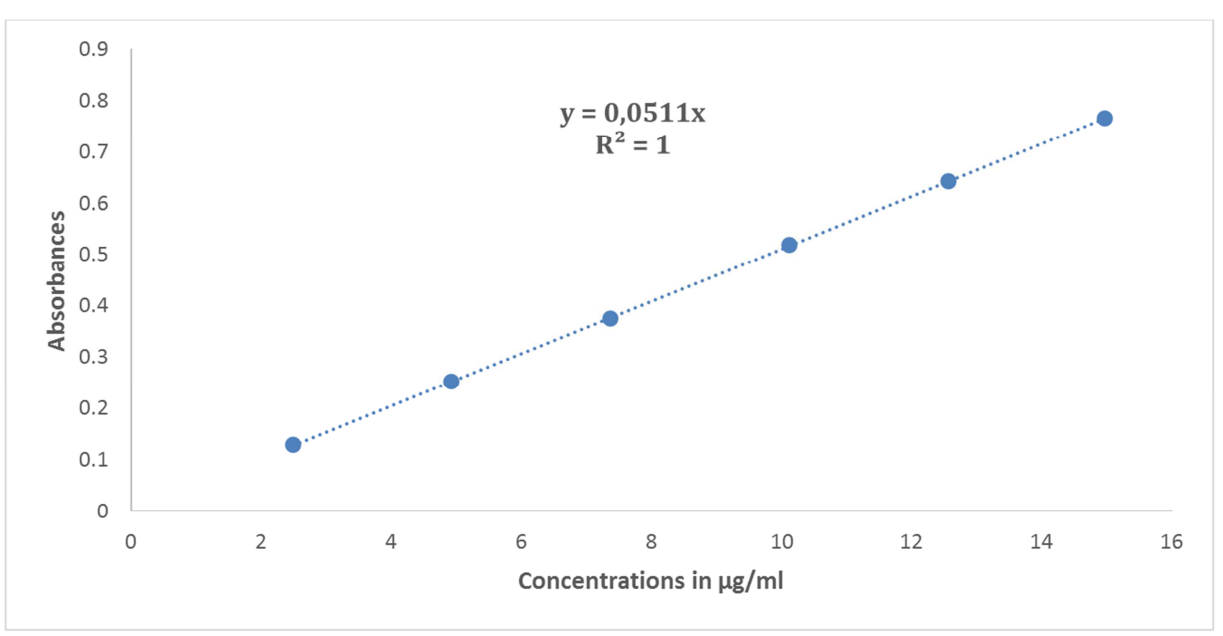

Figure 2. Calibration curve of Cefixim Trihydrate standard solution. 
The method developed showed good specificity by the recovery rate (Table 1) and by the non-absorption of the placebo mixture at the maximum absorption wavelength used in the method (Figure 3).

Table 1. Specificity of the developed method.

\begin{tabular}{|c|c|c|c|c|c|c|c|}
\hline Series & $\%$ Excipient & Standard introduced $(\mu \mathrm{g} / \mathrm{ml})$ & Standard collected $\mu \mathrm{g} / \mathrm{ml}$ & $\%$ Recuperation & Mean & SD & $\%$ RSD \\
\hline & 80 & 10 & 10.09 & 100,90 & & & \\
\hline \multirow[t]{3}{*}{1} & 80 & 10 & 10.00 & 100,00 & 100,50 & 0,45 & 0,45 \\
\hline & 80 & 10 & 10.05 & 100,50 & & & \\
\hline & 100 & 10 & 9,90 & 99,00 & & & \\
\hline \multirow[t]{3}{*}{2} & 100 & 10 & 9,96 & 99,60 & 99,90 & 0,73 & 0,73 \\
\hline & 100 & 10 & 10.03 & 100,30 & & & \\
\hline & 120 & 10 & 10.00 & 100,00 & & & \\
\hline \multirow[t]{2}{*}{3} & 120 & 10 & 10.00 & 100,00 & 100,30 & 0,52 & 5,52 \\
\hline & 120 & 10 & 10.09 & 100,90 & & & \\
\hline
\end{tabular}

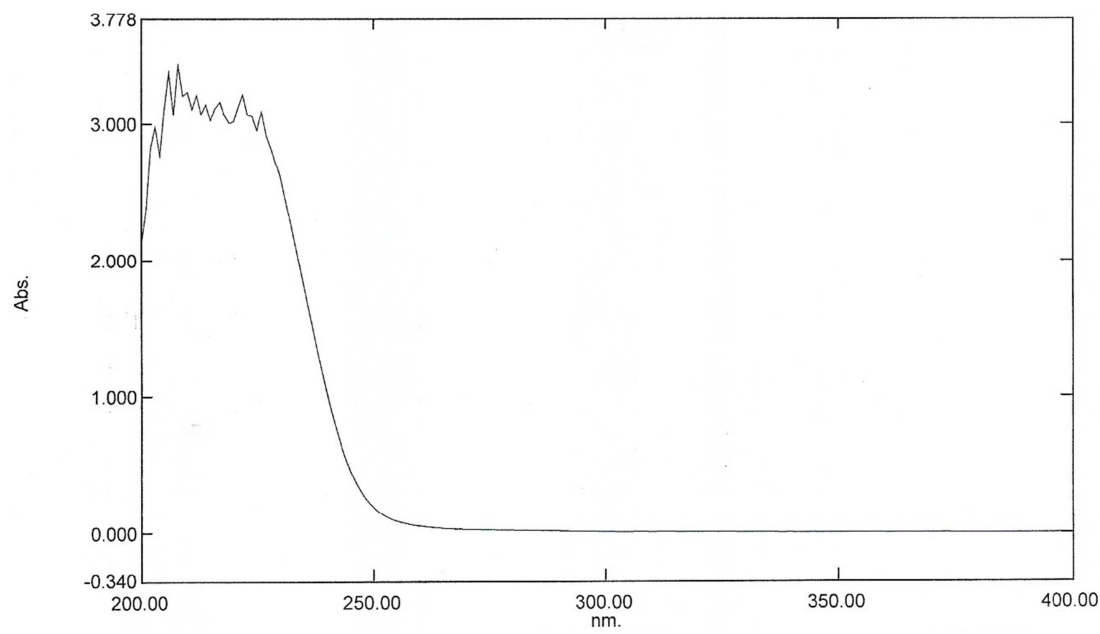

Figure 3. UV/vis absorption spectrum of the placebo mixture.

The method exhibited good intra and inter-day precision, the relative standard deviations (\% RSD) presented in Table 2 were less than $2 \%$.

Table 2. Intra and inter-day precision of Cefixim Trihydrate.

\begin{tabular}{|c|c|c|c|}
\hline Studied parameters & Day 1 & Day 2 & Day 3 \\
\hline Introduced concentrations $(\mu \mathrm{g} / \mathrm{ml})$ & 5 & 10 & 15 \\
\hline Intra-day concentrations found $(\mu \mathrm{g} / \mathrm{ml})$ & 4,98 & 9,96 & 14,86 \\
\hline Recovery (intra-day) & 99,60 & 99,60 & 99,06 \\
\hline Relative Bias (\%) & $-0,40$ & $-0,40$ & $-0,90$ \\
\hline RSD (\%) & 0,096 & 0,119 & 0,107 \\
\hline Inter-day concentrations found $(\mu \mathrm{g} / \mathrm{ml})$ & 4,98 & 9,92 & 14,78 \\
\hline Recovery (inter-day) & 99,60 & 99,20 & 98,53 \\
\hline RSD (\%) & 1,277 & 0,767 & 0,468 \\
\hline
\end{tabular}

The accuracy of the method was evaluated by the metered addition method at three concentration levels $(80 \%, 100 \%$ and $120 \%$ ); the recovery rates and the \% RSD calculated in Table 3, demonstrates the accuracy of the developed method.

Table 3. Accuracy of the method.

\begin{tabular}{|c|c|c|c|c|c|c|}
\hline Serial $\mathbf{N}^{\circ}$ & Analyzed tablets of CEFI-200 $(\mu \mathrm{g} / \mathrm{ml})$ & \%standard added & Standard recovered $(\mu \mathrm{g} / \mathrm{ml})$ & $\%$ recovery & Means \pm SD & $\%$ RSD \\
\hline \multirow{3}{*}{1} & 10,76 & 80 & 7,76 & 97,00 & \multirow{3}{*}{$97,25 \pm 0,25$} & \multirow{3}{*}{0,2570} \\
\hline & 10,76 & 80 & 7,78 & 97,25 & & \\
\hline & 10,76 & 80 & 7,80 & 97,50 & & \\
\hline \multirow[t]{2}{*}{2} & 10,76 & 100 & 9,73 & 97,30 & \multirow[t]{2}{*}{$97,56 \pm 0,38$} & \multirow[t]{2}{*}{0,3881} \\
\hline & 10,76 & 100 & 9,80 & 98,00 & & \\
\hline \multirow{2}{*}{3} & 10,76 & 120 & 11,69 & 97,41 & \multirow{2}{*}{$97,44 \pm 0,38$} & \multirow{2}{*}{0,3857} \\
\hline & 10,76 & 120 & 11,74 & 97,83 & & \\
\hline
\end{tabular}


The robustness of the method was evaluated by measuring the Absorbances of the standard solution of $10 \mu \mathrm{g} / \mathrm{ml}$ at wavelengths of $\lambda_{\max } \pm 1 \mathrm{~nm}$, the relative standard deviations calculated in Table 4 prove the robustness of the developed method.

Table 4. Robustness of the method.

\begin{tabular}{llll}
\hline Serial $\mathbf{N}^{\circ}$ & Absorbance in $\mathbf{2 8 5} \mathbf{~ n m}$ & Absorbance in $\mathbf{2 8 6} \mathbf{~ n m}$ & Absorbance in 287 $\mathbf{~ n m}$ \\
\hline 1 & 0,517 & 0,516 & 0,514 \\
2 & 0,517 & 0,516 & 0,514 \\
3 & 0,518 & 0,517 & 0,515 \\
Means & 0,517 & 0,516 & 0,514 \\
SD & 0,00070 & 0,00070 & 0,00070 \\
\%RSD & 0,1367 & 0,1356 & 0,1361 \\
\hline
\end{tabular}

The application of the developed method for Cefixim quantification in tablets, gave good results as traduced on Table 5 by RSD value.

Table 5. Quantification of CEFI-200 (Cefixim tablet $200 \mathrm{mg}$ ) using the developed method $(n=3)$.

\begin{tabular}{llll}
\hline Theorical concentration $(\boldsymbol{\mu g} / \mathbf{m l})$ & Concentration found $($ in $\boldsymbol{\mu g} / \mathbf{m l})$ & Concentration found (in \%) & SD \\
\hline 10 & 10,777 & 107,77 & 0,295 \\
\hline
\end{tabular}

\section{Conclusion}

A UV/vis spectrophotometric method for the estimation of Cefixim Trihydrate in pure form (raw material) and in its pharmaceutical form (tablets) without interference from the excipients commonly used in formulation was developed.

The study required simple and no sophistic equipment and the hydrochloric acid as dilution solvent which made the process easier and practicable in laboratory.

The speed, simplicity, sensitivity, selectivity, accuracy, precision, reproducibility, robustness and economic character of the developed method allow us to recommend it for the routine analytical control of Cefixim either in pure state or in tablet forms.

\section{Acknowledgements}

We are grateful to the laboratory of Drugs analysis of the faculty of Pharmaceutical Sciences team leaders, who helped us to get appropriate chemicals to conduct this research. Also, we thank the Laboratory of quality control and drugs analysis and diets control where study was conducted, and its analyst's team who were available for this study achievement

\section{References}

[1] European Pharmacopoeia -6th edition.

[2] American Pharmacopoeia 30-NFR25.

[3] British Pharmacopoeia 2012.

[4] Babitan, Abdul Wood Siddiqui, Nisha Gupta, Method Development and Validation for Determination of cefixime in Bulk dosage Form by Spectrophotometry, International Journal of pharmaceutical Sciences Review and Research, 58 (1), September-October 2019; Item No. 03, Pages: 13-16.
[5] Umme Bushra et al., Development and Validation of UV Spectrometric Method for Determination of cefixime trihydrate in Bulk and Pharmaceutical Formulation, Asian Journal of Biomedical and Pharmaceutical Sciences; 3 (22) 2013, 2013, 1-5.

[6] ICH, Harmonized Tripartite Guideline, Validation of Analytical Procedures, Text and Methodology Q2 (R1). (2004).

[7] British Pharmacopoeia 2008

[8] Swiss Accreditation Service SAS, Guide for the validation of chemical-physical test methods and the evaluation of measurement uncertainty, Document No. 324. fW, 2017-11, rev. 03 pp. 22-23.

[9] Ashutosh Kar, Pharmaceutical Drug Analysis-2005, PP. 83-85.

[10] Jean Toullec and Monique Mottet, Quantitative chemical analysis of Vogel, pp. 142-147; 662-665.

[11] Durgesh Rameshlal Parakh, Moreshwar P. Patil, Sandeep S. Sonawane, Chetan P. Jai. Development and validation of spectrophotometric method for estimation of mebendazole in bulk and pharmaceutical formulation, World Journal of pharmaceutical Research, Volume 4, issue 7, 2223-2235, June 2015.

[12] France Corbeil and Elyse Boivin, Validation of an analytical method, National Institute of Public Health, Quebec Public Health Laboratory, Version 04, pp 16.

[13] Dange YD, Honmane SM, Bhinge SD, Salunkhe VR, Jadge DR. Development and Validation of UV-Spectrophotometric Method for Estimation of Metformin in Bulk and Tablets Dosage Form. India $\mathrm{J}$ of Pharmaceutical Education and Research. 2017; 51 (4S): S754-S60.

[14] Jain Nilesh (2010) Spectrophotometric Method Development and validation for Quantitative Estimation of Amlodipine Besilate in Bulk Drug and their Dosage Forms by Using Hydrotropic Agent. Eurasian J Anal Chem 5 (3): 212-217. 
[15] Gajjar Anuradha K, Shah VD (2010) Simultaneous UVspectrophometric Estimation of rosuvastatin and ezetimibe in their combined dosage forms. International of pharmacy and pharmaceutical Sciences 2 (1): 131-138.
[16] Douglas A. Skoog. F. James HOLLER. Timothy A. NIEMAN. Principles From Instrumental Analysis, Tradition and Revision of the 5th American Edition by Claudine Buess-Herman and Freddy Dumont, 1st Edition, 2nd Edition 2012, pp 868-870. 